\title{
Doing Indigenous Community-University Research Partnerships: A Cautionary Tale
}

\author{
Kathleen Absolon, Susan Dion
}

\begin{abstract}
With the intention of generating critical discussion, in this paper the authors examine the complexities of doing decolonizing research within colonial institutions. Drawing on their experiences as co-investigators on a large scale partnership grant involving Indigenous and non-Indigenous partners doing community-based research in Indigenous communities, they tell a cautionary tale about confronting and working through the challenges. Specifically addressing communication, decision-making, internalized colonialism and research relationships, the authors conclude that while these kinds of partnership grants involve struggle, in the end the effort is necessary.
\end{abstract}

KEYWORDS Indigenous, community-based research, decolonizing research, Indigenous community, partnership, internalized colonialism, emancipatory, dialogue

Ultimately, however, I learned that transgression is the root of emancipatory knowledge, and emancipatory knowledge is the basis of a revolutionary pedagogy.

(Sandy Grande, 2004, p.5)

Don't air your laundry in public, tell tales out of school, or talk about what happens behind closed doors. These warnings loomed large as we wavered in our decision to write this paper. For our wellbeing and in service of contributing to revolutionary practice we chose to write. In this article, we examine the complexities of doing decolonizing research in Indigenous communities with a team that includes both Indigenous and non-Indigenous researchers and partners. While there is a growing body of literature addressing principles of doing research with and for Indigenous communities (Castleden, Morgan, Lamb, 2012; Koster, Baccar, Lemelin, 2012; Ninomiya \& Pollock, 2016), we address issues that arise when the research is done by a team that includes both Indigenous and non-Indigenous scholars. As Indigenous co-investigators on the Walking the Prevention Circle: Re-Searching Community Capacity Building for Violence Prevention project, we supported one another and regularly engaged in conversations, examining our experiences and the challenges we encountered while attempting to do community-based research (CBR). In these conversations, we co-created ethical space (Ermine, 2005) where we could talk and be heard from our positions as Indigenous scholars working through the complexities of accomplishing decolonizing research within colonial institutions. Creating space to talk afforded us a pathway to understanding: the place where 
Euro-Western knowledge systems meet Indigenous knowledge systems; the disconnect between our ideals and reality; and, our conflicting relationships to the research process. Our writing provided a venue for identifying and understanding what was happening on our team. With the hope of grounding our analysis in experience, we have included excerpts from our recorded conversations in italicized font. While we agree with Grande that emancipatory knowledge is the basis of revolutionary practice, we also acknowledge our transgression in writing that which exposes failures, grapples with the messiness and examines the nuanced power relationships that represent the real experience of engaged scholarship processes. While the research project continues, shortly after completing this paper, we made the difficult decision to remove ourselves from a project that, while on the way to completion, was from our perspective losing its Indigenous and community-based approach. Our intention is a focused search for understanding process. It is not about holding individuals responsible but rather a consideration of the complexities of doing engaged research for, with and by Indigenous people.

\section{Engaging Ourselves in a Critical Project}

Almost ten years ago we joined a team of academics and program providers interested in learning successful strategies of violence prevention in Indigenous communities. When the team received a SSHRC Partnership grant in the spring of 2012, we began the project feeling both hopeful that our work would contribute to knowledge in service of communities recuperating from colonial violence, and daunted by the task. During the past five years, we have learned more about the complexities of doing collaborative research and less about violence prevention. While we have experienced some success, in many ways, the project has been frustrating, time-consuming and disappointing. We are reflecting and writing to understand and share our learning.

Our commitment to participating in the project of understanding violence prevention in Indigenous communities is deeply embedded in our personal and professional lives. We are both tenured Indigenous scholars working in academic Institutions. Absolon ${ }^{1}$ is Anishinaabe kwe with a passion for Indigenous wholistic practice and methodologies in re-searching from Indigenous places of knowing. Her research and teaching are focused on Indigenous knowledge and methodologies; she has been engaged in community practice, education and Indigenous re-search for 25 years. Dion ${ }^{2}$ is a Potawatami/Lenape re-searcher and educator with mixed Irish/French ancestry working in the field of Indigenous research and education for over 25 years. We use re-search purposefully to indicate our shared commitment to the production of knowledge that is both Indigenous and decolonizing. We hyphenate the word to re-search and in doing so promote an act of looking again at how we search and as we

\footnotetext{
${ }^{1}$ I have known the lead community partner on this project for 20 years. We worked together on Walking the Prevention Circle prior to the start of this project. I did not know the principal investigator or my co-author.

${ }^{2}$ I have collaborated with the principal investigator of this project on one other SSHRC Insight Grant. We have been colleagues for 16 years, and I consider her a mentor. Before the start of this project, I did not know either my co-author or the lead community partner.
} 
"re-search, we re-write and we re-story ourselves" (Absolon, 2011, p. 21) by centering our epistemologies, principles, and methodologies in our search and gathering journeys.

The goal of the partnership project was to "conduct community-based research on how communities mobilize and build capacity through the Canadian and Australian Red Cross Societies' Walking the Prevention Circle (WTPC) -- a model for violence prevention in Aboriginal communities" (Cardinal and Pepler, 2011). ${ }^{3}$ From our perspective, this research presented an opportunity to engage in a project meant to create opportunities for learning from how communities implement WTPC and re-establish wellness. Working within a team model was appealing to both of us. On this partnership grant, the Principle Investigator (PI), a senior university non-Indigenous researcher, is working in collaboration with a Lead Community Partner (LCP) who is an Indigenous person working in a non-Indigenous nongovernmental organization. The Promoting Relationships and Eliminating Violence Network (PREVNet) along with the Canadian Red Cross, both non-Indigenous bodies, provide governance for the project. We were invited to join the project as co-investigators and asked to guide an Indigenous-informed research process. We conceptualized an Indigenous methodology, designed the specific steps and were responsible for training the Community Based Researchers (CBRs) ${ }^{4}$ in the skills of data collection and analysis, along with knowledge and understanding of processes for identifying and presenting their research findings. CBRs are community members identified and hired by the participating communities. The LCP is the National Aboriginal Advisor to the Canadian Red Cross and is the driving force behind W'TPC, a program that focuses on violence prevention education for Indigenous communities. The five-year project work plan entailed an ambitious schedule of program delivery, training community members in CBR methods and documenting and learning from communities' response to the programming they received.

Our vision for this project was to "break through the university's monopoly claim on knowledge and truth" (Van Katwyk \& Case, 2016, p. 28), through a team approach based on Indigenous principles of shared collaboration and equitable decision-making (Horn Miller, 2013). The principles we articulated in our research plan state, "we are drawing on Aboriginal approaches and collaborating to respect Aboriginal values, understanding, methods of researching and decision making" (Cardinal and Peplar, 2011, p. 2). We understood this to mean that the research team agreed to engage in a research process honouring Indigenous ways of knowing and practice. As the Indigenous re-searchers, we took the lead on establishing protocols for our research process and understood that the team was committed to an Indigenous-informed process. Our meetings began with ceremony, in the presence of sacred helpers including an eagle feather, smudge, medicines, drums, and shakers. The presence of this bundle represented our commitment to honouring Indigenous knowledge and the spirit of the project. We regularly led a circle process to invoke inclusivity, equity, collaborative

\footnotetext{
${ }^{3}$ In its original iteration, this project was supposed to involve communities in Australia, but these partnerships did not come to fruition.

${ }^{4}$ In this paper we use the acronym CBR for community-based research and CBRs for community-based researchers.
} 
discussion, and decision-making. Consultations with Indigenous team members were to occur on a regular basis, and the team leaders seemed committed to practices that respect Indigenous values of relationship building, reciprocity and wholistic practice throughout the project. Unfortunately, the team fell short on operationalizing these approaches in the longer term.

Demands from the university and partner institutions surfaced and pressures for more efficient decision-making, budget reductions and a dismissal of epistemological differences of progress over process led to compromising the commitment to Indigenous principles. Repeated conversations and requests to restore and schedule regular meetings and inclusive decision-making practices were disregarded and minimized in the spirit of efficient decision making by the project PI and LCP. In our experiences, Euro-western university researchers tend to default to everyday practices when under pressure to produce results within timelines that do not match Indigenous community or re-search processes. Inequities of voice, process and decision making are still all too common, despite engaging in collaboration and shared decision making that characterize the rhetoric of community engagement (Van Katwyk and Case, 2016). We related to this work as Indigenous researchers who resist Euro-western approaches to both research and project functioning. Accomplishing change in partnership relationships with Indigenous - non-Indigenous team compositions and community-university engagements is challenging work. Indigenous knowledge calls upon all partners involved to sit in circle, invoke the spirit of the project with ceremony and medicines, collaborate, share knowledge and make decisions within the whole. All team members are included in all aspects of the research process, in decision-making and all planning, regarding the direction of the project. Centering Indigenous knowledge, protocols, and practices in re-search requires movement from understanding the value of relationships, reciprocity, respect and equity to enacting them.

\section{Engaging with Our Team and Communities}

Our project story is connected to a larger narrative characterized by the ongoing presence of colonization in our lives. Our lives and hearts' work have been to restore Indigenous identity, land, language, culture, and traditions. We do this through our work as educators, community helpers, and re-searchers. In the academy, our worldviews, languages, traditions, and cultures guide our contributions to restoring the value of Indigenous knowledge. We were invited to be co-investigators because we are Indigenous re-searchers; we had experience with $\mathrm{CBR}$, and we had relationships to the PIs through the WPC program and as colleagues. When invited to participate, we discussed Indigenous principles of practice, and it was on these principles that the project showed promise to decolonize the process and promote Indigenous communitybased wellness. We agreed to participate on the basis that we would be steering Indigenous processes both on the team and in the re-search; and that the Institutional stakeholders would create a pathway for us to lead the Indigenous methodologies. Our knowledge informed the teams' processes concerning circle sharing, discussion, and decision-making. Additionally, our experience and expertise told a re-search process guided by Indigenous research methodologies for a community-based and capacity building project. 
At its core CBR is about centering community needs, creating space for capacity building, and generating restorative relationship processes (Dockstater et al., 2016; Fraser \& Voyageur, 2016). These were also the stated goals of our project, and for us, this meant crafting a research process grounded in Indigenous worldviews. We committed to developing and delivering a community-based research methodology. We believe that community-based approaches can be decolonizing while centering Indigenous ways of searching, and offer two brief descriptions of CBR and Indigenous methods from our project.

The following description of CBR is from the project-training manual we developed to train the Community Based Researchers in CBR, Indigenous research methodologies, ethics and knowledge gathering (Absolon \& Dion, 2015). Essentially, CBR fits nicely with Indigenous ideologies and worldviews because it tends to be community defined and open to Indigenous ways of knowing, being and doing. Within Indigenous communities, the community's wellbeing is a central concern in determining action.

CBR occurs with specific parameters:

- The community benefits from the research,

- The community owns the process and controls the forms of data collection,

- It enhances community capacity and empowers community members,

- It educates, trains and develops skills of community members,

- It facilitates community-based relationships and connections, and

- It is a process that occurs over an extended period.

The research is a decolonization process in which Indigenous peoples do not have to rely on non-Indigenous researchers or to work from a non-Indigenous perspective. CBR allows Indigenous peoples to reclaim their identities, their histories and their understandings of the world around them (Absolon \& Dion, 2015, p. 21).

Engagement is essential to a community-based process that honours the community's timelines and priorities (Lonczak, et al., 2013). Along with other Indigenous researchers including Brant Castellano (2004), Ermine (2005), Kovach (2009) and Wilson (2009), we recognize that engaging people from the communities involved is essential to a communitybased process. We also firmly believe that Indigenous people ought to lead re-search within our communities to produce knowledge that is emancipatory and liberating out of colonialism in all its forms and impacts.

Our goal was to engage members of the communities involved to become CBRs. They are critical to meaningful research as they carry existing relationships, knowledge, and understanding of their community history and context. CBRs are the ones who, with their community, determine the means of gathering. They are involved in all aspects of the project including making meaning and presenting their community's findings. The goals of CBR are achieved through the process of working with CBRs and transferring knowledge of how to gather information and community stories that are respectful and consistent with the community culture (Lonczak et al., 2013). A principle of having CBRs is that they learn to do research that is driven by their community in a manner consistent with their Indigenous worldviews 
and traditions. We introduced and trained the CBRs on Indigenous research methodologies.

We believe that Indigenous research projects must be framed by and rooted in Indigenous epistemologies and methodologies (Absolon, 2011; Kovach, 2009; Smith, 2012; Wilson, 2009). These methodologies, by design, create space for each community to determine which methods will emerge as most useful and this depends on each community's landscape, language, culture, and traditions. Our manual states that "Indigenous methodologies are methods that are wholistic, relational, inter-relational and interdependent with Indigenous philosophies, beliefs, and ways of life" (Absolon \& Dion, 2015, p. 23). From this perspective, our goal was to do on-going capacity building and training throughout the project contributing to the restoration of Indigenous community presence, voice, and process.

\section{Beginning Milestones}

The project started with a five-year work plan outlining the intention of bringing four communities from Canada into the research in Year One; in Year Two we would add a fifth Canadian community and two communities from Australia. We had a reasonably rigorous plan for identifying, hiring and training the CBRs. At the request of the PI and the LCP, we developed an Indigenous tool to help CBRs produce their baseline story. We called this tool the Starting Point Story (SPS). It provided the CBRs with a specific task to begin their work. The tool was included in the Training Manual we developed to train CBRs in data collection. By the end of Year Two, we had hoped to have two CBRs working in each of the seven Indigenous communities involved in the project. Training was supposed to happen in each of the five years. In January of 2014, two years after receiving the grant, we did initial training with only one CBR in attendance. It was a challenge, but we saw it as an excellent opportunity to pilot the manual. A year later, with an improved manual, we conducted a second successful training with six CBRs present. In December 2016, we had a follow-up session, and the CBRs from three communities in Canada presented their Starting Point Stories. With three communities (now four) ready to proceed, the LCP was to deliver the Red Cross Ten Steps training in all four Indigenous communities in Canada during April 2017.

\section{Identifying Moments of Success}

We have a shared vision and a commitment to understanding and contributing to violence prevention within Indigenous communities. We began the project with feelings of promise and hope and probably with naïveté, thinking that it would be productive, rewarding and impactful. We were optimistic because we had existing respectful relationships among the core team members. In our conversation we shared:

\section{We have genuinely shared our work together. Commitment, investment and love for Indigenous people, culture, Creator, land and all that we are moving to reclaim, restore, reconnect and re- search our Indigenous knowledge and ways of being, seeing and doing. Our shared capacity to speak the truth of history, the re-search process and frustrations with working within a colonizer / colonized relationship.}


Working together, we, the co-authors of this paper, have had the opportunity to uphold the value of relational accountability to each other and committed to consulting with one another and to a shared decision-making process. We would not agree to anything without informing and connecting first. Through this, we learned from and with each other and supported each other. Rather than working alone with sole responsibility for reminding, advocating, and teaching others to consider Indigenous people's experiences and perspectives, we collaborated and received many lessons from this project. It has been a significant success.

We approached the project highly invested in the Indigenous CBR process. Working on a national scale with a broad scope was challenging, and it took some time to get the project launched. Start-up challenges meant only starting when CBRs were identified and ready. Delays resulting from events happening in the community took precedence over the research projects' timelines. The research team and research sites span the country, and while there have been challenges, the team has made significant strides. Although our work with the communities has been challenging, we have also had opportunities to work in limited ways with a group of CBRs. Listening to their Starting Point Story presentations was a celebratory moment. We witnessed capacity building in action as the CBRs demonstrated their developing research, writing and presenting skills.

Since the project began, we have witnessed the benefits of employing Indigenous CBRs who have been trained to respectfully hold up their own community's knowledge and history. Our goal as Indigenous researchers was to ensure they benefit from our training and engage with their communities in a manner that respects their community's priorities. How the CBRs have engaged with the process deserves acknowledgment. For example, at a project meeting, we witnessed presentations by the CBRs on their Starting Point Story. The following is a brief description and list of what we observed of their learning. In their presentations the CBRs

- demonstrate that they have become knowledge keepers of their own community's history and facilitate their community's history becoming visible;

- work at sharing the history in their community for their community's benefit;

- together with the team, learn to understand some of the root causes of their community's challenges;

- build and form new relationships with one another that cross language and cultural boundaries;

- oresent their community's story while understanding the forces that challenge their community;

- see their knowledge as valuable to the community leaders to assist with applications for funding and for identifying and responding to community needs;

- show what they learned about working together and sharing knowledge as they created community information banners, posters, and presentations about their community; 
- developed technical skill while working with media, photoshop, graphing and audio recordings;

- searched out and worked with community photographs, newsletters, and historical records;

- $\quad$ shared their learning from community Elders;

- reflected their understanding of how their community changed over time, and

- experienced the power of talking, sharing, learning and growing in their relationship with one another.

$\mathrm{CBR}$, using Indigenous methodologies, is healing and reconnects people to each other, their community's story and journey. It is personal, meaningful and emotional. Despite the differences across the communities, the CBRs all seem to be having rich learning experiences. They have traveled and navigated dogsleds, airports, ferries, and buses, and have managed to make their journies back home. The pathways they are forging are pathways of sharing their histories comprised of land, culture, tradition, colonization and disrupting forces. The CBRs are working hard at restoring their community knowledge about itself and in the process restoring their relationship to each other. During the presentations, one of the CBRs expressed how she now feels visible in her community and that is a dramatic difference for her. Before this project, her experience was one of absence and uncertainty of not knowing her voice or her capacities.

The presentations revealed that in a CBR design using Indigenous methodologies, the impact on learning with the Indigenous CBRs is empowering and their learning evidenced knowledge building and skill development. For us, it was exciting and rewarding. The CBRs have learned so much already, and they have only started their Starting Point Stories; they have become community historians, knowledge keepers and elders in training. The knowledge mobilization has begun, and the beauty of Indigenous methods in a CBR design is that knowledge mobilization is embedded in the process of learning, sharing, and growing within one's community.

\section{Engaging in Process: Identifying Challenges and Tensions}

Competing needs, timetables, and priorities are common sources of discontent on large-scale research teams where to a certain extent challenges are expected. Engaging in re-search with a blended team that involved collaborating with Indigenous communities addressing issues of violence prevention, we were prepared for challenges. Looking back on our project, we have come to understand how unresolved problems became sources of serious tension. Drawing on Dockstater et al. (2016), who describe their own challenging experiences doing research that crosses academic-Indigenous community boundaries, we now turn our attention to identify and discuss critical challenges we encountered. Our experience of the project was impacted by core differences in worldviews, language, pace and protocols, political, academic and social pressures, and capacity issues. 


\title{
Challenges of Scope and Interest
}

As Indigenous researchers invited to participate in a project that included communities spread across a large geographic area, we believed that we could develop a hybrid model of CBR that would work. If the communities were seriously committed to the project, the challenges of distance and differences would be manageable. A hybrid model would require investment in relationships between the funded academic researchers and the communities. Our first step was to develop the CBR training manual (mentioned earlier) on CBR, Indigenous research, ethics and data collection and do so in a relevant manner. As we worked, we were challenged not only by the distance and differences between the communities involved but by the distance between the communities and ourselves. The gap was both material and ideological. While they had agreed to the research project, their capacity for and commitment to CBR was unclear.

At the time of writing this paper, challenges with community engagement were increasing as was our frustration, rooted in what we were experiencing as a loss of commitment to the process. As time passed without significant progress, pressures from the funding agencies and partner institutions were contributing to the collapse of a process that was supposed to be driven by Indigenous values and methods. As pressure mounted, the team leaders resorted to 'taken for granted' ways of working that resulted in a return to researching colonized ways. A challenge that seemed to be rooted in the project scope became a tension rooted in lack of progress caused by a lack of attention to relationships and a commitment to CBR principles.

\section{Challenges of Community Ownership}

Reflecting on our experiences as co-investigators on this project our primary concern was with making progress in a good way.

\begin{abstract}
There is a gap in the relationship between the lead Indigenous researchers and the CBRs. This gap is reflective of and contributing to a problem. Over the years there has been little opportunity for us to meet with the CBRs in the communities, to see Walking the Prevention Circle training in action, to understand and support the community engagement process. How and why should the communities trust the process if they've never met the Indigenous researchers on the project? How are the CBRs supposed to connect with us if we have never been to their communities? Who has cultivated relationships of trust with the communities or is this also part of the problem? Maybe this relationship doesn't exist?
\end{abstract}

For us, community ownership of, commitment to, and investment in the research process are required for a successful project. When our training sessions were scheduled, rescheduled and then rescheduled again, we came to realize that there was a problem. We asked ourselves "Are the communities genuinely committed to doing both the Walking the Prevention Circle program and the research? Was a lack of commitment contributing to the delays?"

Issues of community ownership were further exacerbated by distance between the communities and us. While we were providers of the research model and the lead instructors for the CBRs, we were not on the front line establishing relationships with the communities 
nor were we invited to travel to and meet with the communities involved in the project. The unpredictability of community engagement required flexibility and adaptability; as experienced researchers, we were aware of those needs. We know that community timelines are more important than the institutional deadlines; however, the lack of community ownership of the research and the lack of connection between the Indigenous researchers and the communities added to tensions between the research team partners.

\section{Tensions Resulting From the Research Team's Lack of Investment in Process}

As time passed, we found ourselves conversing with each other in an attempt to understand our increasing frustrations. Progress on the project was stalled, and we did not know what was going on in the communities. Collaborative research projects are often structured in such a way that team members are dependent on each other for access to the community sites. In our project, this contributed to the creation of tensions within the team. Cultivating positive relationships based on trust between all members of the research team and the communities is necessary to avoid gatekeeping as a strategy of control. We tried to engage with the team, we were committed to the time and energy required, but our research partners dismissed our calls for regular meetings to discuss the challenges. As Koster, Baccar, Lemelin, 2012) observe, "The research interaction must be based on respect and trust, where the community knows the researcher and the purpose and intent of his/her work and they approve" (p. 209). Clarifying roles and responsibilities is a positive and proactive step, yet in many cases this process breaks down. Excluding team members from access to the research sites, failing to make time for discussion and decision-making about schedules, budgets and changes to the project focus can be particularly damaging to research team relationships and threaten the possibility of accomplishing project goals.

Investigating the layers of frustration, confusion and lack of progress in accomplishing our research, we came to realize that not all team members were comfortable with the CBR model, nor were they ready to commit the time and energy required to make the process work. While we knew from the start that members of our team were coming to the table with different objectives, we thought that a hybrid model of CBR was going to be possible. We now realize that our purposes were not only different, they conflicted. Burnette \& Billiot (2015) explain that mainstream and Indigenous researchers often come to projects with differing ideas of purpose: "mainstream research may focus on knowledge development, whereas Indigenous research may focus on making meaningful contributions to the Indigenous community along with knowledge expansion" (p. 6). These observations expose different ideas about what knowledge matters. Within the mainstream construct, researchers want knowledge about the community to justify or promote a particular program. Ultimately the research is intended to construct knowledge that serves the researchers' objectives. Indigenous CBR focuses on communities creating knowledge that is of use to the community (Smith, 1999). Finding a process capable of sustaining both researcher and community needs requires patience, respect, time, energy, and a willingness to work in service of accomplishing each other's goals. In essence, it requires the creation of ethical spaces where "researchers and community members 
[are able to] acknowledge and accept differing worldviews and address unequal power relations (Broad \& Reyes, 2008, p.130). We recognized the need for dialogue and reflection in a research project aimed at transforming colonialism and power relations. It seemed that our partners did not understand that our requests for increased engagements and meetings would facilitate a much needed ethical space.

Tensions in language and wording. Wording and language differences emerged throughout the project. One example is that in our project, the mainstream researchers wanted us to develop a 'baseline data' instrument. As Indigenous researchers working outside of an empirical frame, the notion of starting with a measurement of the community's state so that one could then measure the impact of a program felt like an alienating and pathologizing step, and we resisted creating one. In response to this challenge, we reframed the idea of a baseline to fit our practice and used language that reflected the CBR process by developing a tool we named the Starting Point Story. Rather than a measurement tool, we created a tool that allowed CBRs to tell their community's story.

As the project progressed, we experienced tensions related to letters of consent. We proposed that the communities use their language and words for their consent forms (if they were going to use them) and debated with team members about this issue. We worked to reframe language in our training manual to be accessible and relevant to our CBRs. At times these conversations with the larger team were tense, and it was at these times that we began to see that power and decision-making was shifting.

Tensions in communication and in decision making. In our conversation about communication and decision-making, we shared our frustrations.

\begin{abstract}
Communication between the research team is an ongoing challenge. We press for opportunities to express concerns we want to refocus on the original intention of the project. We speak up - wanting to meet and resolve confusion, frustration and team disconnection. Our questions and concerns about process including community control, researchers learning and capacity building along with relationships between team members are lost in the demand to meet deadlines and accomplish outputs.
\end{abstract}

On this project, we were caught off guard when significant decisions were made in the absence of whole team discussions. It contributed to the distress and anxiety we associate with the project. On a regular basis, we, the co-authors, met and discussed issues. In the absence of full team meetings, we created space to connect, step outside of our experience, critically reflect and apply a decolonizing analysis. For us, this shift felt empowering and hopeful that change was possible. We were working to construct critical understandings and move forward.

Although the team had a stated commitment to implementing an Indigenous model of decision-making, we frequently found a colonial hierarchical, top-down process being used. Being at the bottom of the top-down model positions us as having to bear the weight of decisions made in the absence of our input. We are critical of this model and believe the process fosters complacency and even rebellion (Horn Miller, 2013, p. 117). 


\title{
Engaging in Decolonizing and Building Insight
}

\begin{abstract}
We are paying attention to the way internalized colonialism operates within each of us. Even as we work to understand it, colonialism continues to impact our actions and interactions particularly when we are working within institutions steeped in colonial practices.
\end{abstract}

The struggle within our project was a struggle for decolonizing and Indigenizing research and knowledge production. Looking back, we see our conversations as acts of seeking truth out of colonialism; writing about it is our transgression; emancipatory knowledge emerges from critical reflection and analysis. In order to understand the experiences that are at times confusing and frustrating, we have turned to critical liberation theorists (Memmi, 1965; Freire, 1970; Littlebear, 2000; Grande 2004), and our Elders (Dr. Jo-anne Dellaire, Dr. Duke Redbird, Dr. Lauri Gilchrist, Herb Nabigon ban and Banakonda Kennedy Kish Bell) who have laid foundations of dialogue and consciousness-raising. Decolonizing requires us to re-examine our situations and remain committed to developing a critical consciousness. As Memmi (1965) explained, it is possible to have contempt for the colonizer and experience admiration and attraction at the same time. We admire the space our non-Indigenous peers occupy while striving to carve spaces for our Indigeneity to dance and sing from who we are, not what others think we should be. We can be critical of the structures of colonialism and reach for transformation within them. As lead researchers, we worked to promote equity through circle work and by appreciating all voices in discussions related to the project. We could look the other way and remain silent so as not to generate discomfort within the team but to ignore colonialisms' presence would be dismissive of an opportunity for critical growth and the sharing of 'emancipatory knowledge.' Working within colonial settings, none of us can entirely escape its grip on how we relate and operate (Friere, 2008; Memmi, 1965). Decolonization requires a commitment of time, energy and process to work through the intersections of personal internalization of colonizer, colonized, oppressed, oppressor, and all the possible external manifestations that emerge in team dynamics. Decolonizing re-search calls for a shift in how people relate and respond to those who occupy the role of boss, power holder or decision maker. Colonial modes of decision-making are a stark contrast to democratic models existing within Indigenous knowledge systems (Horn Miller 2013). Our critical consciousness, decolonizing and Indigenizing selves fuel essential encounters that shift the colonial norm. We question and press for change in our work together. The macro aggressions of colonization upon Indigenous peoples are replicated in micro contexts such as research teams. The reality is that when pressures build and demands increase, Indigenous methods and Indigenous researchers become cumbersome, get compromised and that which is comfortable, familiar and efficient dominates.

For us, Indigenizing means that we are actively relearning our languages, cultures, and Indigeneity to inform how we engage in research. More specifically, it was crucial that Indigenous knowledge and principles of equity, inclusivity, voice and circle work informed our team's research process. Our role as Indigenous re-searchers was to consciously reach for 
reclamation of Indigeneity. We are now investigating the structures we want to transform out of, including-for example-how the demands of SSHRC grants and academic institutions create parameters that don't nurture authentic process, community engagement, or time for dialogue collaborative knowledge construction. With a blended team and diverse community and institutional partners, dilemmas emerge that challenge the relationships and principles of $\mathrm{CBR}$, and the reality is often there are no guidelines to navigate difficult issues. The literature reflects that we are not alone in navigating landscapes where the nuances, undercurrents and unpacked ideologies of decolonizing re-search present challenges, are messy, and require pauses, dialogue and time to work through rough patches (Dockstater et al., 2016). Knowing key principles is not sufficient, and we suggest that improved transparency and systems that acknowledge specific markers of authority reproducing relationships of power, and control in research involving Indigenous people are necessary to improve practices (Ninomiya \& Pollock, 2016; Van Katwyk \& Case, 2016). While conflicts and tensions are inevitable in CBR, it is how these uncomfortable moments are addressed that matters (Kovach, 2009). In our view, making these moments transparent is a useful exercise. As more researchers and community stakeholders write frankly about their positionality, challenges, and solutions to the lived realities of putting Indigenous CBR concepts and principles into place, the more we will further the work of decolonizing research (Ninomiya \& Pollock, 2016, p. 35).

Challenges experienced in this project are also rooted in the worldviews, experiences, and perspectives that team members bring to the work. These differences impact our ways of communicating, our actions and interactions, our priorities and decisions. Although the project began in a good way, as time passed with little progress being made, we saw signs that pointed to a lack of support for Indigenous methodologies. We engaged in this project because of its intentions. We are passionate about projects that work to reclaim our ancestral memories and place within Creation (Hampton, 1995). Projects rooted in a desire to decolonize, Indigenize and promote anti-colonialism at all levels of work are worthy of our time and energy. Burnette and Billiot (2015) explain, "Unless the intricacies and complexities of conducting research with Indigenous communities are deconstructed, they may well serve as barriers to the broader project of decolonization, and decolonization is integral for the improved well-being of Indigenous peoples" (p. 2) and all people. We all need to work at being consciously aware of the complex histories, values, goals aspirations, fears, and anxieties that impact team and community partnerships for better or worse.

We also had to look in the mirror unpacking and understanding our experiences. We are reflecting on how constraints on our time impacted the project and contributed to the issues and challenges.

We are asking ourselves how we are implicated in disrupting the team. Our schedules are busy, we both have other commitments, we're not the PIs on this project consequently we have to be PI on other projects and this project doesn't get the time and attention from us that it deserves. We are reliant on the PI and the LCP to manage the budget, community engagement and cultivate community relationships. Most importantly we are relying on the 
leadership team to have trust in the CBR process and build trust in the communities. Are we asking too much? How can the leadership team trust a process that they don't know or understand?

Tensions in Indigenous-mainstream research contexts are difficult to navigate and require time and attention. It is the responsibility of researchers to create time and space to critically reflect, discuss and make decisions together (Burnette \& Billiot, 2015). Research teams comprised of both Indigenous/non-Indigenous members researching Indigenous communities must have ongoing discussions about who is driving the project and whose agendas are being met. If knowledge produced through research is going to be of use to Indigenous communities, it must be framed by Indigenous and decolonizing frameworks; otherwise it is merely another case of hegemonic knowledge production.

\title{
Engaging with Consciousness: Our Words of Caution
}

\begin{abstract}
At this moment in the project we feel silenced, and there is no space to talk about power, control, bierarchy and the ongoing imposition of colonizing ways of working together. We are coming to understand that our ways of being and doing are made difficult by requirements and frameworks imposed on us by the non-Indigenous institution including research granting institutions.
\end{abstract}

We believe that working through challenges requires ongoing dialogue and team-based decision-making. The values we maintained in our process have been our openness to discussion and decision making with each other, a commitment to being available to meet and plan, and a willingness to deconstruct and engage in critical decolonizing conversations. In this section, we provide a series of cautions to researchers who are committed to this practice. While it is challenging and tensions arise, we still believe it is possible and worth the struggle. Having learned some lessons, we are now sharing them here.

\section{Consciously Consider Invitations to Collaborate}

We get invited to work on projects led by non-Indigenous academics. It is alluring because the pressure to produce and engage in research is a reality for all of us in the academy. Young Indigenous scholars are vulnerable to being invited to participate and add Indigenous presence on research projects. In spite of the pressure to engage, take the time to consider the degree to which one's input will be included. When invited to collaborate, discuss issues of community ownership and investment and ask how the process of community engagement will unfold. Engage in conversations about who is leading the project, what the motives are and who will benefit from this search. Talk about issues of power in process and decision-making. These are all legitimate conversations when considering an invitation to collaborate. 


\section{Assert Yourself on the Team}

Identify research assistants and other necessary support you will require. Assert your right to a budget and initiate conversations about processes related to conflict resolution, team protocols, and decision-making. Doing Indigenous non-Indigenous research in Indigenous communities is complicated, and issues of power and control will surface. Be aware of the tendency for self-doubt, for questioning legitimacy of place and propensity to attribute the confusion to one's own inability to understand the research language, process or material. This tendency can fuel non-productive anxiety, frustration, and exasperation. Exercise caution when invited to participate or when inviting others to join as the Indigenous "expert" on a research grant. It can be difficult to say no to senior colleagues especially when they are also your mentors and friends. Joining research partnerships needs to be done with careful consideration and project protocols in place. Ask about writing, decision-making practices and access to funds. Be aware of time commitments and the implications of not having enough time.

\section{Engage with Critical Reflection and Conscientious Unpacking of Colonial Methodologies}

Talk about decolonizing and anti-colonial methods and take the time required to engage in decolonizing spaces. Discuss Indigenous scholarship to gain an appreciation and understanding of team members' awareness of critical Indigenous perspectives and knowledge relative to Indigenous re-search. Not all people wanting to engage in Indigenous research partnerships are taking the critical steps necessary to decolonize and work in anti-colonial ways. We encourage potential teams to talk about this and to discern if team members are on their journey of decolonizing. Are principles of dialogue and critical reflection embedded in the teams' process of working together and is this important to your philosophy of research? Are team members willing to talk about their fears, capacities and what they will bring and contribute to the project?

\section{Engage in Meetings and Discussions about How the Research Methodology and Process May Unfold}

Talk about language, terminology, and wording. Have conversations that deconstruct language and meaning behind the use of jargon and alienating terms. Make use of Indigenous language translations as a tool to clarify definitions. In terms of re-searching and affirming Indigenous values and priorities related to process and protocols, don't let the funding grant deadlines generate pressure to default to the PIs. If a project team wants to do a CBR methodology, it is crucial that all partners invest in the time to discuss and understand what it is they are seeking to accomplish. Partners must understand and be knowledgeable about CBR and how to work with CBRs. They must have knowledge and faith in the process, in the value of Indigenous knowledge and protocols and understand how to be supportive in all areas of the research. When timelines are stressed, don't allow the process to be compromised for the sake of Institutional pressures. 


\section{Engage in Conversations about the Scope of the Project and What is Realistic}

Time and distance warrant questions, and we caution researchers that projects that are national or international in scope require time and travel. Is there room in the project budget to support you and the commitments that are crucial to authentically nurture relationship building across time and distance by all members of the research team? Know that you have choice as an Indigenous researcher on an interdisciplinary team and that you are not bound to consent to what is familiar.

Indigenous and non-Indigenous partnerships must be grounded in Indigenous knowledge, worldviews and practices and research must be done in service of restoring humanity based on respect, love, humility, courage, truth, honesty and wisdom.

\section{Conclusion}

Our cautionary tale is told to generate critical discussions and contribute to creating consciously responsive and responsible research partnerships. We described how we become intertwined within academic organizations, SSHRC funding structures and the partnerships between individuals, organization, and communities. The layers and interplay within and amongst the multiplicity of relationships create a complex myriad of challenges and tensions. Challenges, when unattended, result in tensions that can unravel a team. We paid attention to our emotions and read them as a signal that there was something wrong. We chose to learn from and make sense of what we were experiencing. This process of critically deconstructing our experience aids in bringing balance to experiences of disempowerment, marginalization, and exclusion. Our analysis has moved from feelings of uncertainty toward understanding.

Having done the work of learning, we are compelled to share what we have learned even when running the risk of transgression. We are responsible for asking how to apply our understanding to create change. Through this paper, we have created time and space for critical reflections on our experiences. Paulo Freire (2008) teaches that with love and humanizing encounters, the oppressed will liberate their oppressor and that dialogue, reflection, and action are pathways to emancipating ourselves from internalized colonialism in how we engage in our partnerships. The positions we occupy on this project and in life matter. We are committed to accessing the power to speak and assert difference in service of accomplishing research that will be of use to Indigenous communities.

\section{Acknowledgment}

We would like to acknowledge the opportunity we were offered by the PI and LCP on our SSHRC Partnership Grant. We're learning a lot from the process. Miigwech / Anushiik! 


\section{About the Authors}

Kathleen Absolon (corresponding author) is an Indigenous (Anishinaabe) researcher and educator. She is the Associate Dean and an Associate Professor in the Aboriginal Field of Study, MSW Program in the Faculty of Social Work at Wilfrid Laurier University. The land and her culture guide her practice as an Indigenous wholistic practitioner, educator and Indigenist re-searcher. Email: kabsolon@wlu.ca

Susan Dion, $\mathbf{P h D}$ is an Indigenous (Lenape-Potawatomi) researcher and Associate Professor, teacher-educator at York University. Her teaching and research focus on understanding the representation of Aboriginal people and the relationship between Indigenous and nonIndigenous people in Ontario's publicly funded schools.

\section{References}

Absolon, K. (2011). Kaandossiwin: How we come to know. Winnipeg: Fernwood Publishing.

Absolon, K., \& Dion, S. (2015). Gathering learning stories: Community-based researcher's training manual. Understanding Community Processes that Promote Wellness Through Walking the Prevention Circle: Re-searching Community Capacity Building Project. Unpublished.

Brant Castellano, M. (2004). Ethics of Aboriginal research. Journal of Aboriginal Health: Victoria1(1), 98-114.

Broad, G. \& Reyes, J.A. (2008). Speaking for Ourselves. A Colombia-Canada Research Collaboration. Action Research. Vol 6(2). 129-147.

Burnett, C., \& Billiot, S. (2015). Reaching harmony across Indigenous and mainstream research contexts: An emergent narrative. Journal of Indigenous Social Development, 4(1), 1-15.

Canadian Red Cross. (2001). Walking the revention Circle. (2nd Ed.). Victoria, B.C.: Canadian Red Cross.

Canadian Red Cross. (2009). Ten steps to creating safe environments for children and youth. Victoria, B.C.: Canadian Red Cross.

Cardinal, S. \& Pepler, D. (2011). Walking The Prevention Circle: Re-searching community capacity building for violence prevention SSHRC Grant Application.

Castleden, H., Morgan, V. S. \& Lamb, C. (2012). "I spent the first year drinking tea": Exploring Canadian university researchers' perspectives on community-based participatory research involving Indigenous peoples. The Canadian Geographer 56(2), 160-179.

Dockstator. J. S., Eabametoong First Nation, Misipawistik Cree First Nation, Opitciwan Atikamekw First Nation, Sipekne'katik First Nation, T'it'q'et, Lillooet BC, Gérard Duhaime, Charlotte Loppie, David Newhouse, Frederic C. Wien, Wanda Wuttunee, Jeff S. Denis, Mark S. Dockstator. (Spring 2016). Pursuing mutually beneficial research: Insights from the Poverty Action Research Project. Engaged Scholar Journal: Community-Engaged Research, Teaching, and Learning, 2(1), 17-38. 
Ermine, W. (2005). Kwayask Itôtamowin: Indigenous Research Ethics: Report of the Indigenous Peoples' Health Research Centre to the Institute of Aboriginal Peoples' Health and the Canadian Institutes of Health Research.

Fraser, J., \& Voyageur, E. (2016). Crafting culturally safe learning spaces: A story of collaboration between an educational institution and two First Nation communities. Engaged Scholar Journal: Community-Engaged Research, Teaching, and Learning, 2(1), 157-166.

Freire, P. (2008). (30th Anniversary Ed.). The pedagogy of the oppressed. New York: The Continuum International Publishing Group Inc.

Grande, S. (2004). Red pedagogy: Native American social and political thought. Lanham: Rowman and Littlefield.

Hampton, E. (1995). Memory comes before knowledge: Research may improve if researchers remember their motives. Canadian Journal of Native Education, 21, 46-54.

Horn Miller, K., (2013). What does Indigenous participatory democracy look like? Review of Constitutional Studies, 18(1), 111-132.

Koster, R., Baccar, K., \& Lemelin, R. H. (2012). Moving from research ON to research WITH and FOR Indigenous communities: A critical reflection on community-based participatory research. The Canadian Geographer, 56(2),195-210.

Kovach, M. (2009). Indigenous methodologies: Characteristics, conversations, and contexts. Toronto: University of Toronto Press.

Little Bear, L. 2000. Jagged worldviews colliding. In M. Battiste (ed.), Reclaiming Indigenous voice and vision (pp. 77-85). Vancouver, British Columbia, Canada: UBS Press.

Lonczak HSV, Thomas LR, Donovan D, Austin L, Sigo RLW, Lawrence N the Suquamish Tribe. Navigating the tide together: Early collaboration between tribal and academic partners in a CBPR study. Pimatisiwin: A Journal of Aboriginal and Indigenous Community Health. 2013;11(3):395-408.

Memmi, A. (1965). The colonizer and the colonized. Boston: Beacon Press.

Ninomiya, M. E. M. \& Pollock, N. J. (2016). Reconciling community-based Indigenous research and academic practices: Knowing principles is not always enough. Social Science \& Medicine, 172, 28-36.

Smith, L. T. 1999. Decolonizing methodologies: Research and Indigenous peoples. New York, N. Y: Zed Books Ltd

Smith, L., T, (2012). (2nd ed.). Decolonizing methodologies: Research and Indigenous peoples. New York, NY: Zed Books Ltd.

Van Katwyk, T. \& Case, R.A. (Fall 2016). From Suspicion and Accommodation to Structural Transformation: Enhanced Scholarship through Enhanced community-university relations. Engaged Scholar Journal: Community-Engaged Research, Teaching, and Learning, 2(2), 25-43.

Wilson, S. (2009). Research as Ceremony: Indigenous Research Methods. Winnipeg: Fernwood Publishing. 